\title{
AN ATTEMPT TO ESTIMATE THE TRUE RATE OF MATERNAL MORTALITY, SIXTEENTH TO EIGHTEENTH CENTURIES
}

\author{
by
}

\section{B. M. WILLMOTT DOBBIE*}

AN ENQUIRY into family structure in previous centuries reveals evidence of the high price in women's lives of replenishment of the population. It could not be otherwise, for when Nature failed in her task, or was thwarted by such adversities as pelvic deformity or malpresentation, attempts to help were mostly fumbling in the dark, literally and metaphorically, and well-meant interference was almost certain to introduce infection, so often fatal.

The study that follows is based upon parish registers, and it must be prefaced with a reminder that exact truth is unattainable; most of the data are flawed, some seriously. Nothing better than an informed estimate can be hazarded, using such solid facts as can be gathered, and not scorning crumbs of evidence. This paper draws attention to some sources of error.

The subject of childbirth deaths in past centuries has not received much attention; in fact, little is known in any quantitative sense, and the difficulties of collecting and interpreting evidence are daunting.

\section{DEFINITION OF MATERNAL MORTALITY}

The question must be considered: for how long after childbirth may death of the mother be the consequence? The International Federation of Gynaecology and Obstetrics includes deaths up to forty-two days after delivery or termination, though accepting that later fatality is possible. The triennial reports into maternal deaths in England and Wales' include deaths up to a year, but usually have the advantage of an autopsy, and reject deaths obviously unconnected.

This criterion cannot be strictly applied in the present study, for the age at baptism is not usually known. The Prayer Book of 1549 enjoins baptism on the first Sunday or holy day after birth, the 1662 book allows to the second Sunday. Registers which give the age of the infant make it clear that the rule was not always kept, and the administration was often later, especially in the eighteenth century; but if the child were likely to die it might be baptized at home on the day of birth. Berry and Schofield ${ }^{2}$ have studied the subject. Their conclusion is that "there was a great variety *Mrs. B. M. Willmott Dobbie, M.A., F.R.C.S., Gattrell, Steway Lane, Batheaston, Bath BAI 8EH. (Hon. Cons. Obstet. \& Gynaec., United Birmingham Hospitals.)

'Report on confidential enquiries into maternal deaths in England and Wales 1973-1979. London, HMSO, 1979.

2 B. Midi Berry and Roger S. Schofield, 'Age at baptism in pre-industrial England', Population Studies, 1979, 25: 463-474. 


\section{B. M. Willmott Dobbie}

in baptism practice in different parishes at all periods: in some parishes baptism took place early, while in other parishes it was late. In some parishes baptism occurred fairly consistently after a certain interval, while in other parishes there was a wide variety of ages at which children were baptised".

Unfortunately, no information is to be found in the registers used for this study; calculations perforce are made from the date of baptism, and death within forty-two days is counted as maternal mortality. (Victims of puerperal sepsis may linger longer than forty-two days after birth, even today. In the latest triennial report, three women, after spontaneous delivery, died of puerperal sepsis after forty-four, forty-nine, and seventy-two days.) In earlier times, for obvious reasons, burial shortly followed death.

Though some registration was undoubtedly conscientious, scrupulous work was certainly not the rule at all times and in all places. Clergy could be careless, parish clerks barely literate. Errors, omissions, and dubieties must be accepted as part of the inherent uncertainties.

\section{CONTEMPORARY EVIDENCE}

Evidence on maternal mortality in the sixteenth century comes from the register of St. Botolph without Aldgate. ${ }^{3}$ From 1583 to 1599, there were 3,236 baptisms and 76 maternal deaths; that is, 23.5 deaths per thousand baptisms.

The London Bills of Mortality are another early source. ${ }^{4}$ Taking every fifth year from 1666 (avoiding the plague year) to 1758 , there were 296,810 baptisms, and 4,720 women recorded as dying in childbed, a rate of 15.9 per thousand baptisms.

Both sets of figures are at best approximations. Not all children born were baptized by the Church of England, though all burials should have been recorded. Probably most of the deaths at parturition or shortly after were counted, but the catastrophes of the early months, such as fatal abortion and ectopic gestation, must often have gone unrecorded, indeed unrecognized. What would now be accepted as late deaths would probably not be noted. In fact, both the births and the maternal deaths are certainly underestimates.

The earliest figures published by the Registrar General, without definition, refer to the year 1840. From then until the end of the century, the recorded death rate varied between four and six per thousand live births. The true rate was probably higher. Williams ${ }^{5}$ found convincing evidence that better certification accounts for the seeming lack of improvement during the century. From 1900 to 1930 , the rate was constant at about $4 \cdot 25$. From then on, antenatal care, better obstetrics, and then antibiotics transformed midwifery, and the present figure for England and Wales is 0.11 per thousand total births (excluding abortion).

\section{THE SCOPE OF THE STUDY}

The work reported here is an attempt to shed a gleam of light on the hazards of maternity in the sixteenth to the eighteenth centuries. It is based on the outcome of

\footnotetext{
"Thomas Rogers Forbes, Chronicle from Aldgate 1583-1599: life and death in Shakespeare's London. New Haven, Conn., Yale University Press, 1971, p. 106.

4 William Heberden, $A$ collection of the yearly bills of mortality from 1657 to 1758. London, 1759.

'William Williams, Deaths in childbed. Milroy Lectures at the Royal College of Physicians, London, $\mathrm{H}$. K. Lewis, 1904.
} 


\section{An attempt to estimate the true rate of maternal mortality, sixteenth to eighteenth centuries}

746 fertile marriages, that is, marriages leading to at least one live birth, resulting in 2,795 baptisms, in three Somerset parishes. The numbers are not large enough to justify any conclusions on the relative quality of midwifery, nor is it likely that the practice of ages changed much during the period. There is no evidence here for improved midwifery. The rate of known and putative deaths for the first and second half-centuries of the Batheaston enquiry was the same; for Bath Abbey there were more deaths in the second half, while the worst period for Wedmore was the last one (1751-1760). (See Table 1.)

The parishes of Batheaston, Bath Abbey, and Wedmore have registers which have been transcribed and indexed. Batheaston is an ancient parish three miles to the east of Bath. The inhabitants were engaged mostly in agriculture, with remnants of the cloth trade; there was close association with Bath, and in consequence some residents of a superior class. Batheaston was chosen for the first study because the writer already had wide acquaintance with the parish records, ${ }^{6}$ which proved useful. The first register book is lost, the second was often poorly kept, until the arrival of a new vicar in 1691 . So, taking 1692 as the starting date, a hundred years were searched; towards the end of the eighteenth century evidence of careless recording began to appear.

The register of Bath Abbey dates from 1569. The search began with 1601 because it is difficult to check earlier identities in the absence of the mother's name from baptism entries, and the register was not always well kept.

Wedmore is at the centre of a remote area on the Somerset levels. Its register reaches, and mostly maintains, a high standard; it was decided to study four ten-year periods, well spaced.

The plan was to seek the outcome of every marriage recorded in the parish register - that is, all baptisms, and the deaths of children or either parent. There were many couples of whom nothing further is known, especially among those married at the Abbey and for a time at Batheaston. Bath was thronged with visitors in the eighteenth century, and a great many names in the register are not local, while the muchrespected vicar of Batheaston celebrated a long run of clandestine marriages until the Hardwicke Act of 1753 put a stop to them.

It is necessary to draw attention to a possible source of bias. When both parties were not "of this parish", it was the custom for the marriage to take place in the woman's parish, and often the first child was brought there for baptism. (This may account for some of the cases where only one child was baptized.) Persons not dying in their own parish might be brought "home" for burial, and there is evidence in the registers studied that this was sometimes the case. When the couple lived elsewhere, burial would often be in the husband's parish, and his death would therefore escape notice in this enquiry.

Families were excluded when there was reasonable doubt of identification: the Lewis, Fisher, and Cannings families of Batheaston defy disentanglement. Families were discarded when several deaths in a short period, including husband or wife or both, pointed to an infection. All parent deaths were tested for a period of unusually high mortality shown by the burial register, and the family excluded when there was

'Beatrice Willmott Dobbie, An English rural community: Batheaston with S. Catherine, Bath University Press, 1969, pp. 60, 105. 


\section{B. M. Willmott Dobbie}

doubt. In fact, in the whole enquiry, few deaths of adults under observation corresponded with an epidemic. So infections such as influenza and typhus do not play a part. Plague visited Bath in 1604,1625 , and possibly in $1643,{ }^{7}$ but carried off none of those concerned in this study. Finally, in three couples both partners died within six months of each other, a suspicious circumstance, one pair being buried on the same day; these, too, were discarded.

Table 1. The scope of the study

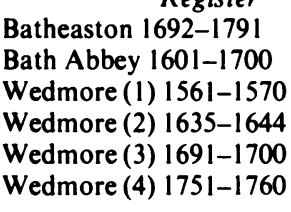

\begin{tabular}{ccc} 
Fertile marriages & Baptisms & Known deaths \\
235 & 889 & 7 \\
245 & 976 & 9 \\
63 & 236 & 3 \\
63 & 214 & 0 \\
74 & 235 & 2 \\
66 & 245 & 6 \\
\hline 746 & 2,795 & 27
\end{tabular}

Note: in a few instances burial, not baptism, of child is recorded.

\section{ONE APPROACH. TERMINATION OF MARRIAGE BY THE DEATH OF EITHER PARTNER} DURING THE MAIN CHILD-BEARING YEARS

Tables 2 and 3 and Figure 1 relate to the numbers of deaths for the first fifteen years of marriage. A startling contrast between man and wife is revealed: seventy-one more women than men were dead, the greatest disparity within the first five years and especially in the first year. Evidence follows which indicates that disasters of pregnancy were probably responsible for the difference.

Other causes of death which may affect men and women unequally, of course require consideration.

Table 2. Termination of Marriage (Death of one partner within fifteen years)

\begin{tabular}{|c|c|c|c|c|c|c|c|c|}
\hline & \multicolumn{2}{|c|}{ 0-1 year } & \multicolumn{2}{|c|}{$0-5$ years } & \multicolumn{2}{|c|}{$5-10$ years } & \multicolumn{2}{|c|}{$10-15$ years } \\
\hline & Husband & Wife & Husband & Wife & Husband & Wife & Husband & Wife \\
\hline Batheaston & 2 & 10 & 12 & 27 & 5 & 17 & 7 & 13 \\
\hline Bath Abbey & 5 & 7 & 13 & 20 & 9 & 16 & 7 & 7 \\
\hline Wedmore (1) & 0 & 3 & 5 & 10 & 3 & 2 & 2 & 4 \\
\hline Wedmore (2) & 1 & 2 & 3 & 5 & 5 & 4 & 6 & 5 \\
\hline Wedmore (3) & 0 & 3 & 2 & 10 & 5 & 3 & 4 & 4 \\
\hline Wedmore (4) & 0 & 2 & 0 & 4 & 5 & 9 & 1 & 5 \\
\hline & 8 & 27 & 35 & 76 & 32 & 51 & 27 & 38 \\
\hline
\end{tabular}

Marriages terminated by death of husband . . 94 Marriages terminated by death of wife $\quad$. . 165

'John Shrewsbury, History of bubonic plague in the British Isles. Cambridge University Press, 1971, pp. $278,339,404$. 
An attempt to estimate the true rate of maternal mortality, sixteenth to eighteenth centuries

Figure 1. Termination of Marriage Death of one partner within fifteen years

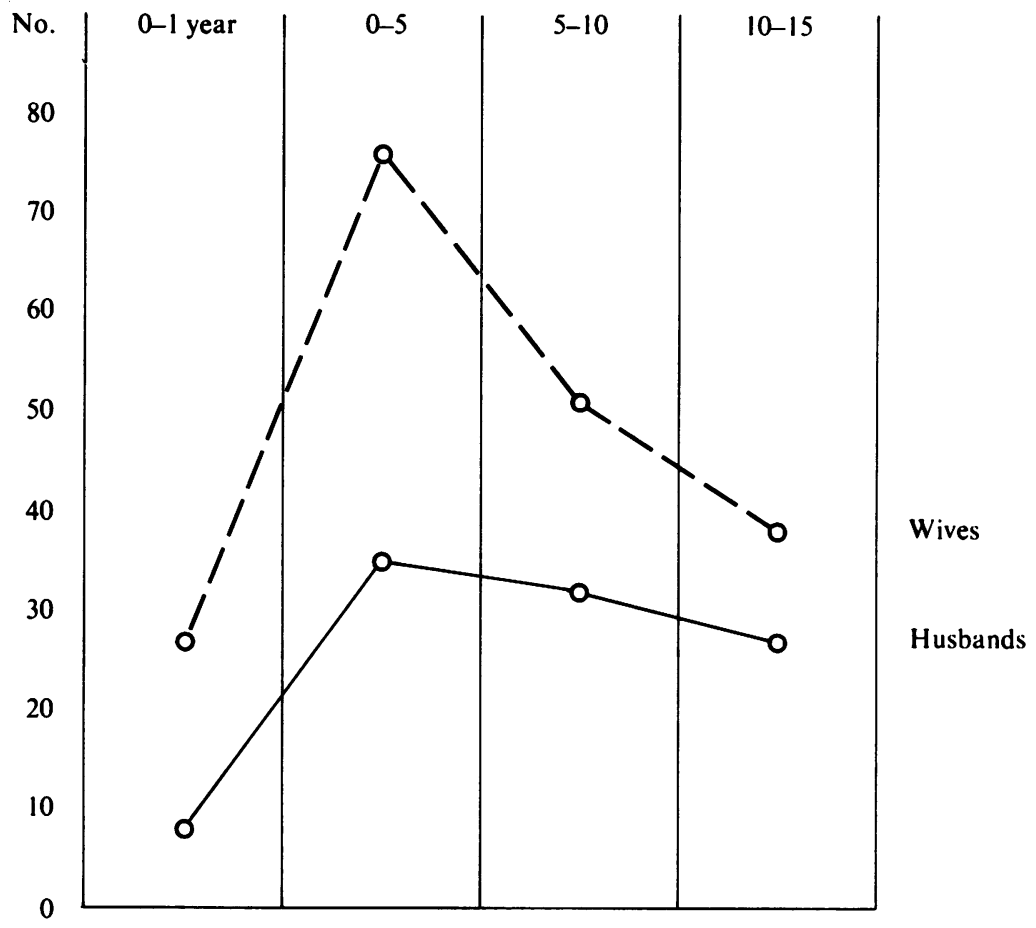

Table 3. Termination of Marriage Cumulative deaths within fifteen years

Termination by death of husband Termination by death of wife

\begin{tabular}{c|c|c|c}
\hline $0-1$ & $0-5$ & $5-10$ & $10-15$ \\
\hline $1.07 \%$ & $4.07 \%$ & $8.98 \%$ & $12.60 \%$ \\
$3.62 \%$ & $10.19 \%$ & $17.16 \%$ & $22.12 \%$ \\
\hline
\end{tabular}

\section{Age at marriage}

The ages of couples at first marriage in Batheaston have been worked out. The median from 1692 to 1741 was: male twenty-six, female twenty-five; from 1742 to 1791 , male twenty-four, female twenty-three; so age difference had no perceptible effect there; though a few men remarrying after the death of a first, or even a second wife, had run their course farther. (Two men each lost two wives in childbirth and lived to marry again.) 


\section{B. M. Willmott Dobbie}

\section{Smallpox and tuberculosis}

The main infections which may affect unequally young men and young women are smallpox and tuberculosis. For the former, Dixon ${ }^{8}$ has reviewed the literature. Women were vulnerable, especially when pregnant, with a high death rate, and usually loss of the child. The registers of the three parishes provide no evidence, for smallpox deaths were not entered as such. A search of the registers of ten parishes in and around Bath discovered that in four of them at some time in the seventeenth or eighteenth century smallpox deaths were noted. The many infant deaths were distinguished, but no ages of adults were given. A total of nineteen men and twelve women died of smallpox. (There were some small epidemics among children, but the adult deaths were mostly isolated.) The greatest number, fourteen men and nine women, came from the village of Freshford, where smallpox deaths were distinguished between 1739 and 1763. Two inferences may be drawn from this admittedly scanty evidence: at one death a year smallpox was not a major cause of adult mortality in mid-eighteenth-century Freshford; and male deaths exceeded female.

Razzell9 quotes Creighton ${ }^{10}$ suggesting a nation-wide mortality from smallpox of 16.5 per cent. Some interesting evidence comes from the overseers' books of Batheaston. Between 1702 and 1788, there were twenty-three episodes when they were concerned to supply medical attention, food, or nursing by paupers immunized by an attack; but only nine, one a vagrant boy, were buried by the parish. No person considered in the present study was among the families named. In 1788, fifty-two poor people were inoculated, "smallpox being in several parts of the parish". The tone of the entry does not suggest that the form was virulent, and there was no excess of burials at that time. The inference is that smallpox was not a grave threat to life, though, of course, a fatality in a pregnant woman may be hidden here and there.

Evidence about the history of tuberculosis in England before the nineteenth century is scanty: the diagnosis was wrapped up in all kinds of oddities. Forbes ${ }^{3}$ gives "con" (consumption, convulsions, or either?), pining and long sick, King's evil. The writer is aware of no early figures which relate to age or sex. According to Roger Des Prez," the disease became epidemic with the industrial revolution, bringing crowding in unhealthy conditions by day and by night.

The Registrar General's figures, from 1840, report a higher mortality in females than in males at ages fifteen to twenty until nearly the end of the century, while men aged twenty to twenty-five were the more susceptible throughout. The figures can only be approximate: diagnosis was given by the next of kin, and cannot always have been correct. There are no grounds here for making allowance for any sex bias in the present enquiry; but it would, of course, be foolhardy to argue from these figures to earlier centuries, as a change in incidence between the sexes in the nineteenth century warns. It seems that evidence for greater susceptibility of young adults of either sex is inconclusive.

\footnotetext{
'Cyril Williams Dixon, Smallpox, London, Churchill, 1962, pp. 113, 326.

'P. E. Razzell, 'The smallpox controversy', Local Population Studies, 1974, 12: 42-44.

${ }^{10}$ Charles Creighton, $A$ history of epidemics in Britain 1666-1893. 2 vols., Cambridge University Press, 1891-94; reprinted, London, F. Cass, 1965, vol. 2, p. 518.

"Roger Des Prez, in P. B. Beeson et al., (editors), Textbook of medicine. Philadelphia, W. B. Saunders, 1975, p. 482.
} 


\section{An attempt to estimate the true rate of maternal mortality, sixteenth to \\ eighteenth centuries}

\section{Violent death}

It would be no cause for surprise if men were more exposed than women to violent death, accidental or other. None of the registers of the main study notes more than an occasional accidental death, but a search of the other ten local registers mentioned found entries relating to seventy-eight men and twenty women. Drowning was easily the most frequent cause - the Bristol Avon in the vicinity of Bath is an obvious hazard. There were many fatal accidents with horses and wagons, and some men died in quarries. Mention of suicide in either sex is rare.

So it seems that disasters of pregnancy caused at least the difference in mortality of husbands and wives during the main childbearing period, perhaps more. If four known maternal deaths after more than fifteen years of marriage are added, maternal mortality for the series would be 26.8 per thousand baptisms.

\section{AN ALTERNATIVE APPROACH. LIMITED FAMILY RECONSTRUCTION}

\section{Direct evidence of maternal death}

Table 4 shows the burials of mothers within a year of a baptism. Twenty-seven fell within the definition adopted - almost ten per thousand baptisms. In view of the latest triennial report (above) it is probable that some, at least, of the remaining fifteen deaths within a year were, in fact, the sequel of the birth; even in recent times, that is, before the antibiotic age, the victims of puerperal sepsis not rapidly fatal might linger until worn out by chronic suppuration.

Table 4. Mother's Burial within a year of Child's Baptism

\begin{tabular}{lr} 
Same day & 9 \\
1-7 days & 4 \\
1 week -1 month & 10 \\
1-2 months & 4 \\
2-3 months & 5 \\
3-6 months & 3 \\
6-12 months & 7 \\
\hline Total & 42 \\
\hline
\end{tabular}

Ten women died following a live birth during the first year of marriage; (up to a quarter of all the women were pregnant at the time of marriage.) This high incidence illustrates the greater risk of a first pregnancy against the relative safety of later ones; that is, of course, until the "grand multipara" again faces notorious danger. (Figure 2, Numbers 8 and 9.)

Twenty-five pairs of twins were baptized, and two of the mothers died (Fig 2, Numbers 5 and 17). Twin births are hazardous to the woman, especially for the risks of malpresentation and postpartum haemorrhage. They are hazardous, too, for the infants, especially the second one, which, as every obstetrician knows, may be lost through separation of the placenta after the birth of the first child, and before delivery of the second. This means that the survival of one child only is not uncommon: if the mother dies, her death is associated with a single baptism. The incidence of twin pregnancy is about one in eighty, so the expected number in this series would be about 


\section{B. M. Willmott Dobbie}

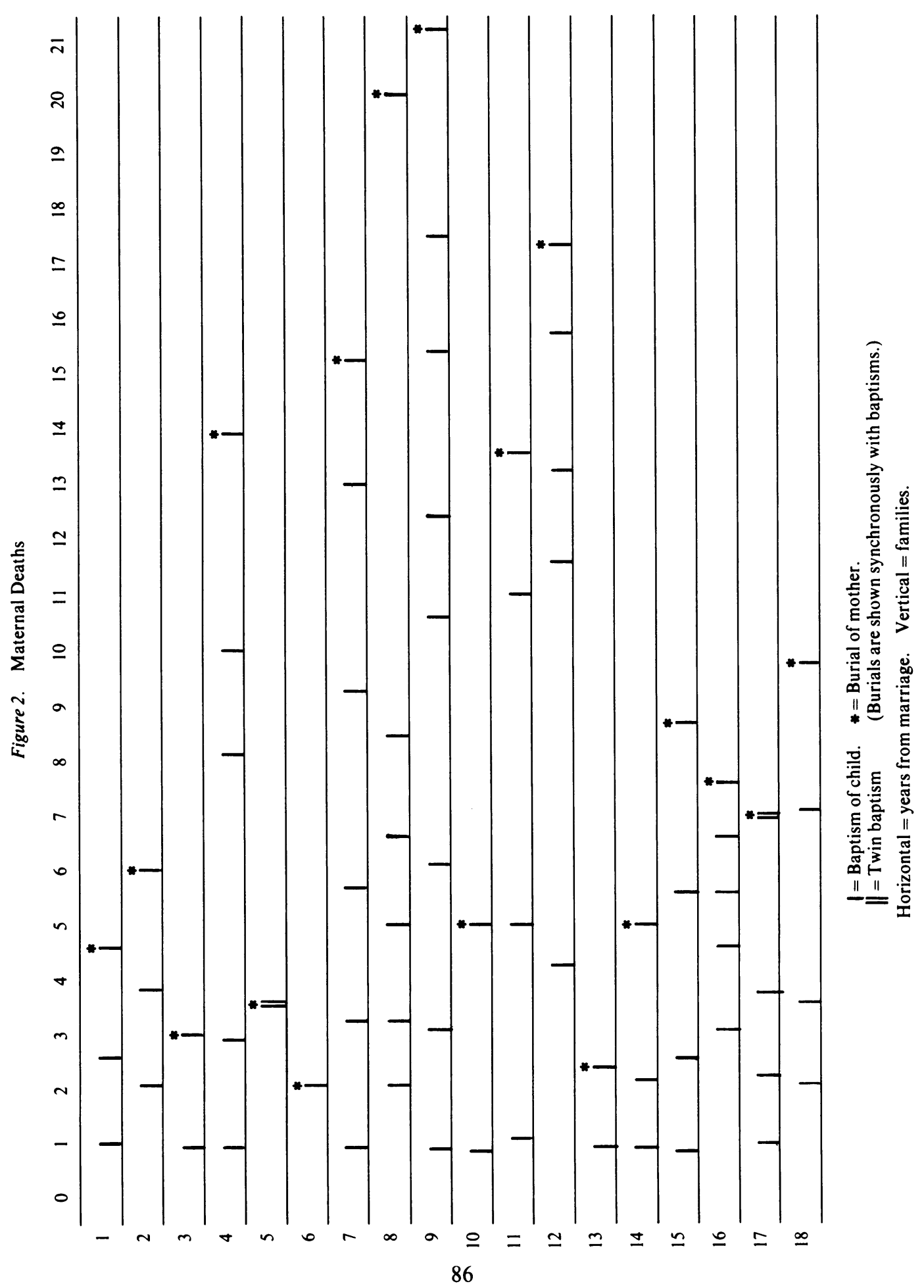




\section{An attempt to estimate the true rate of maternal mortality, sixteenth to eighteenth centuries}

thirty-five. The difference between twenty-five and thirty-five illustrates the point. It is quite likely that a maternal catastrophe attended other twin births.

\section{Putative maternal mortality}

The birth of a live child without the knowledge and aids of modern obstetrics implies more or less normal mechanics of labour. If for some reason, such as disproportion or malpresentation, labour was obstructed, the usual consequence was a stillbirth or death of the mother undelivered. Rickets, the main cause of a deformed pelvis, was well known in the seventeenth century. Glisson's classical work ${ }^{12}$ was published in 1650 , though he does not seem to have recognized that infantile rickets was the precursor of a deformed pelvis.

It is true that progress was being made; the more advanced man-midwives understood podalic version and delivery by the breech. It might save the life of the mother, but it is noteworthy that Percivall Willughby (1596-1685), a keen advocate of version, who described several cases so treated, did not claim that the child survived: that must have been a rare triumph.

Willughby was perhaps the most enlightened man-midwife of the seventeenth century. He was a man of excellent humanity, whose advice to midwives was to avoid active interference if possible, and to use all gentleness. His admirable recipe was "knowledge, charity and tender compassion" - and prayer. An excellent observer, who kept full records of his cases, he was well acquainted with the mechanics of labour, normal and abnormal, and gave careful directions for diagnosing and dealing with abnormalities. (It is the more surprising that when a happy outcome followed the administration of one of the frightful concoctions in vogue, he uncritically accepted the propter hoc conclusion.)

In his Observations in midwifery, ${ }^{13}$ Willughby remarked that women who delivered themselves unassisted usually did well; that is, were spared infection. He confessed that haemorrhage was a problem beyond his powers: "I hold the flux of blood deadly, if it be great, I never heard of any woman that escaped, but that they all perished. Many have perished through this sad accident and usually it proves fatal to all women. If possible, I heartily could wish, that some worthy practicer would be pleased to direct some powerful ways, or medicines, to bridle this raging destroying evil. Women would have cause to acknowledge his worth, and all succeeding ages would give him thanks.... I confess my ignorance, and I believe, that there is no other, but God alone, that can do this work, to help the woman."

Willughby's works remained in manuscript until 1863. The writer is acquainted with one of the three known copies of his 'The Country midwives opusculum or vade mecum', in manuscript, of course, and much worn. It can scarcely have been generally familiar to midwives. Indeed, Willughby remarked that many of them could not read.

It must not be forgotten that, though knowledge was expanding, informed

\footnotetext{
${ }^{12}$ Francis Glisson, De rachitide sive morbo puerili qui vulgo The Rickets dicitur tractatus, London, F. G. Bate and A. Regemorter, 1650; translated by P. Armin, enlarged and corrected by N. Culpeper, London, 1651.

${ }_{13}$ Percivall Willughby, Observations in midwifery and the Countrey midwives opusculum and vade mecum, Boston, Mass., Charles River Books, 1976, pp. 5, 11, 13, 106, 120, 199, 201, 305-308.
} 


\section{B. M. Willmott Dobbie}

practitioners were few, and certainly not available except in centres of population. It is known that a great deal of "meddlesome midwifery", explicitly deplored by Willughby, went on, and the woman who had the services of a professional did not necessarily benefit. In most places a local woman did the best she could with the very minimum of knowledge. Some of Willughby's accounts are horrifying.

If the child could not be delivered, nothing remained but destruction, if the mother's life was to be saved. It requires a brisk imagination to picture such an enterprise, the operator armed with nothing but a knife, or possibly scissors, a crochet, perhaps only a hazy notion of the mechanics of delivery, working on an exhausted but conscious patient. As is well known, the obstetric forceps, invented in the seventeenth century, remained a secret until the eighteenth, to the everlasting shame of the family who kept the secret.

Over all childbirth hung the terrible menace of infection. Even in normal cases, the vagina was repeatedly smeared with such materials as butter, goose grease, capon's or hen's fat, or whole egg. Operative procedures almost inevitably meant infection, nothing was known of the need for cleanliness, and yet another fatality threatened. (Even into this century, half of maternal mortality was caused by puerperal sepsis.)

Only rarely, in a few registers, and usually over a short period, does an entry "in childbed", without a baptism to correspond, tell the sad tale. Evidence must be sought elsewhere. Nothing can be known of the frequency of abnormal labour; something can be said, however, on the association of stillbirth with death of the mother. Eccles ${ }^{14}$ has published some figures from three parishes where such a record was kept. Maternal deaths, per thousand stillbirths were:

$\begin{array}{lrr}\text { Sedbergh, Yorks. } & 1700-1750 & 57 \\ \text { Cartmel, Lancs. } & 1664-1675 & 64 \\ \text { Crosthwaite, Cumb. } & 1629-1729 & 137\end{array}$

The figures show the danger to the mother when the child was stillborn: far greater than with a live birth; exactly as would be expected. (The numbers of stillbirths and proportion of the total births are not given.)

The present enquiry provides some evidence on maternal death without a baptism to draw attention to it. Besides the ten who died after bearing a live child in the first year of marriage, a further seventeen were buried. It can scarcely be doubted that a catastrophe of pregnancy accounted for many, if not most, of these deaths, and for others without issue in the second year. Of course, a previously childless woman also may lose her life as the result of pregnancy in later years of marriage (see Figure 2, Number 5).

When the mother of a young family died and there was no baptism, the pattern is often suggestive. Comparison of Figures 2 and 3 bears this out. Figure 3, No 18 is shown for its resemblance to Figure 2, No 8. The usual spacing of pregnancies to women in their prime was about twenty-four to thirty months, less if the child died, ovulation being resumed in the absence of suckling. Sometimes a gap in the sequence indicates an unsuccessful pregnancy; Figure 3, Number 11 is a good example.

If space allowed, Figure 3 could be extended to include a total of fifty-six women with a typical pattern of pregnancy ending in their deaths. Suppose half of these, and 


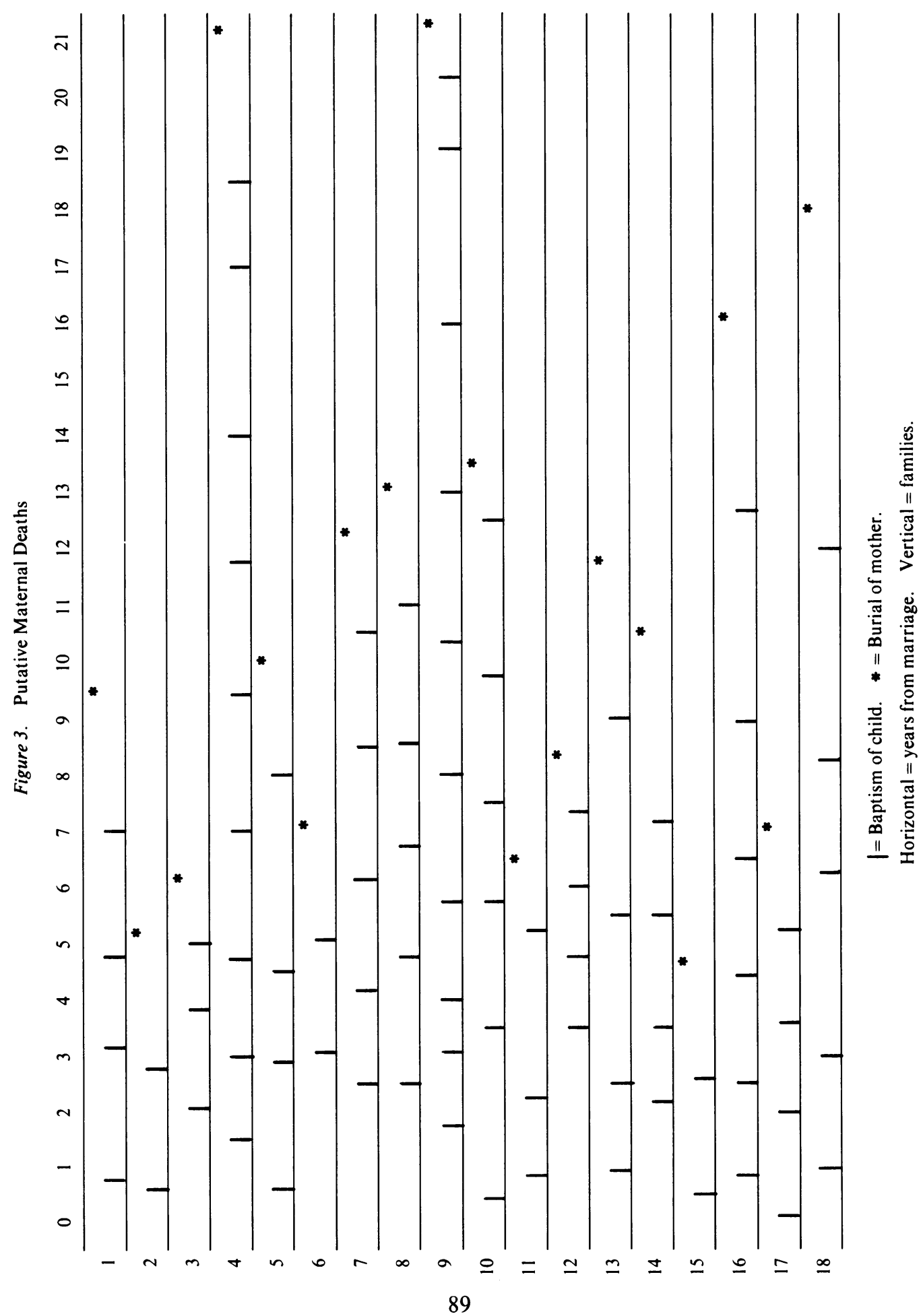




\section{B. M. Willmott Dobbie}

half of the deaths without issue in the first two years of marriage were the consequence of pregnancy, probably not an over-estimate, forty-one are added to the known toll: 14.7 for every thousand baptisms, making a total of 24.4 per thousand baptisms. If two-thirds of the deaths were so caused, the figure becomes 29.4.

This evidence is a necessary corrective of more optimistic estimations. It follows that many an obstetric tragedy of motherhood is remembered only by an entry such as "M- wife of J-S-" in the burial register. Eccles ${ }^{14}$ mentions the figure 10-15 deaths per thousand births "based on typical parish registers" supplied to her by E. A. Wrigley of the Cambridge Group for the History of Population and Social Structure; this figure approximates that derived from known deaths in the present series, and is certainly much too low, as an estimate of total maternal mortality (see p. 85).

\section{SUMMARY}

The study is based on the registers of three Somerset parishes between the sixteenth and eighteenth centuries.

Two lines of approach were employed. The first was a comparison of the death rates of husbands and wives during the first fifteen years of marriage. The estimate so obtained is 26.8 maternal deaths per thousand baptisms. The second was based on limited family reconstruction, and it is suggested that the figure probably lies between 24.4 and 29.4 per thousand baptisms.

Admitting the unavoidable uncertainties in both branches of the study, the fact that both, based on independent $a$ priori argument, arrive at substantially the same answer suggests that it is not far from the truth.

14 Audrey Eccles, Bull. Soc. social Hist. Med., 1977, 20: 10.

\section{News, Notes and Queries}

\section{ROYAL COLLEGE OF PHYSICIANS OF EDINBURGH}

On 6-11 September 1981, the College celebrated the tercentenary of its foundation in 1681. More than three hundred delegates from over thirty countries gathered in Edinburgh for a commemorative congress. Congress themes included the history of the College and of medicine in Scotland, the role of the College in medical education and organization at present and in the future, recent advances in medicine, and reports on research undertaken by Fellows and Members throughout the world. Participants in the programme included in addition to Fellows and Members, representatives from many other colleges and academies of medicine. The University of Leiden, the Pharmaceutical Society of Great Britain, the Royal Botanic Garden, and the Scottish Society of the History of Medicine also collaborated, and exhibitions concerning the history of medicine were arranged by the Scottish Record Office and by medical and publishing companies. 